\title{
Effects of dietary fishmeal substitution with corn gluten meal and poultry meal on growth rate and flesh characteristics of Chinook salmon (Oncorhynchus tshawytscha)
}

\author{
Katarina H. Doughty $\cdot$ Shawn R. Garner (1) - Mark A. Bernards • \\ John W. Heath $\cdot$ Bryan D. Neff
}

Received: 3 May 2019/Accepted: 26 August 2019/Published online: 11 September 2019

(C) The Author(s) 2019

\begin{abstract}
There is considerable interest in developing diets that maintain growth performance and market appeal for salmon aquaculture while relying less on fishmeal as a major ingredient. Here, we compared growth rate, survival, fat content, tissue colouration and carotenoid levels (astaxanthin) in Chinook salmon (Oncorhynchus tshawytscha) fed two diets. The first diet was a typical commercial salmon diet with $59 \%$ fishmeal content, while the second diet reduced the fishmeal content to $15 \%$ (75\% reduction) and substituted $28 \%$ corn gluten meal and $16 \%$ poultry meal. Over an approximately 14 -month growth period, we found no significant difference between fish fed the high fishmeal or low fishmeal diet in either growth rate or survival. Individuals fed the low fishmeal diet did have $25 \%$ higher total body fat percentage than those fed the high fishmeal diet. Individuals fed the low fishmeal diet also had flesh that was significantly less red than fish fed the high fishmeal diet. Carotenoid analysis confirmed that the change in tissue colour was the result of reduced astaxanthin levels in salmon fed the low fishmeal diet. Due to the importance of red tissue colour for the market appeal of salmon, the corn gluten and poultry meal diet is not viable for salmon aquaculture in its present formulation, but our results suggest further modifications to the diet that could mitigate this effect.
\end{abstract}

Keywords Chinook salmon · Aquaculture diets · Poultry meal · Corn gluten meal · Carotenoids · Astaxanthin

\author{
Abbreviations \\ HPLC-MS High-performance liquid chromatography mass spectrometry \\ MtBE Methyl tert-butyl ether \\ PIT Passive integrated transponder \\ YIAL Yellow Island Aquaculture Limited
}

K. H. Doughty · S. R. Garner · M. A. Bernards · B. D. Neff ( $₫)$

Department of Biology, Western University, London, ON, Canada

e-mail: bneff@uwo.ca

J. W. Heath

Yellow Island Aquaculture, Heriot Bay, BC, Canada 


\section{Introduction}

Salmonid aquaculture has historically relied on feeds that include fishmeal as the principal ingredient (Gatlin et al. 2007). However, many fisheries that support fishmeal production are in decline, leading to decreased availability and increasing costs of fishmeal and fish oil (Gatlin et al. 2007). There is thus a need to identify alternative protein sources that can serve as a replacement for fishmeal in salmonid feeds. Ultimately, the feasibility of incorporating alternative protein sources into salmonid feeds will depend on the effects of those feeds on key aquaculture performance traits such as survival, growth rate, fat content and tissue colour.

A number of studies have shown that survival is not affected by incorporating alternative protein sources into aquaculture diets. For example, plant-based protein sources had no effect on survival in Atlantic salmon (Salmo salar) (Mundheim et al. 2004). Diets that incorporated poultry protein sources also had no effect on survival in rainbow trout (Oncorhynchus mykiss), even when fish were experimentally challenged with a pathogen (Sealey et al. 2011). Similarly, diets that replaced fishmeal with a combination of poultry and plantbased ingredients were associated with no change in survival in either Atlantic salmon (Burr et al. 2012) or rainbow trout (Burr et al. 2012; Lu et al. 2015).

Arguably, the most important trait when assessing alternative feeds in aquaculture is growth rate. Feeds that include plant protein sources, such as soybean meal or corn gluten meal, have previously been shown to lead to reduced growth rate in Atlantic salmon and rainbow trout (e.g. Mambrini et al. 1999; Mundheim et al. 2004). Feeds that include poultry protein sources have shown mixed effects on growth; replacing 40-50\% of fishmeal with poultry meal had no effect on growth rate in rainbow trout (Steffens 1994; Sealey et al. 2011), but replacing $30 \%$ of fishmeal with poultry meal led to significantly lower growth rates in Chinook salmon (Oncorhynchus tshawytscha) (Fowler 1991). Combining poultry and plant-based protein sources has shown promising results: Atlantic salmon diets that replaced $50 \%$ of fishmeal with soy and poultry meals (Hatlen et al. 2015) or rainbow trout diets that replaced $75 \%$ of fishmeal with soy, corn and poultry meals (Lu et al. 2015) led to growth rates equal to the control diets. Based on these results, salmonid diets that include a mixture of plant and poultry proteins sources appear to have the potential to maintain normal growth rates in aquaculture.

Replacing fishmeal with alternative protein sources can result in altered body composition, specifically fat content, which influences tissue texture, flavour and subsequently market appeal (Gatlin et al. 2007; Bjerkeng et al. 1997). Plant protein sources have a low crude lipid content, which must be supplemented, commonly using fish oil, to create a balanced fatty acid profile (Gatlin et al. 2007; Parés-Sierra et al. 2014). In contrast, poultry meal has a high crude fat content, and its inclusion in alternative aquaculture diets at levels as low as $25 \%$ has led to increased body fat in Atlantic salmon and rainbow trout (Sealey et al. 2011; Steffens 1994). The effect on body fat content of diets that use a combination of plant and animal protein sources have not yet been assessed.

A major concern in diet formulation for salmonids is the maintenance of red flesh colouration. Astaxanthin is the primary carotenoid responsible for this red colouration and is also a major precursor to vitamin A (Anderson 2001; Saez et al. 2016). In previous studies of rainbow trout, diets that included plant protein sources, mainly corn gluten meal, were associated with reduced tissue colouration relative to fishmeal diets (Saez et al. 2014, 2016). This difference may occur because corn gluten meal contains high levels of yellow xanthophylls (lutein and zeaxanthin; 150-500 mg/kg) (Park et al. 1997; Moros et al. 2002), which do not impart the same red flesh colouration and could limit astaxanthin uptake due to passive interference during digestion (Furr and Clark 1997; Olsen and Baker 2006). The effects of diets containing poultry meal on salmonid flesh colouration have not been assessed, but minimal effect on tissue colouration is predicted because poultry meal contains few carotenoids that could limit astaxanthin uptake due to passive interference (Moreno et al. 2016). The effects of diets containing both corn gluten meal and poultry meal on flesh colouration are uncertain.

Currently, there are no studies assessing the efficacy of a combination protein source diet for Chinook salmon aquaculture. In this study, we examine the effects of using a combination of corn gluten meal and poultry meal to replace $75 \%$ of the fishmeal in an aquaculture diet fed to Chinook salmon. Specifically, we analyse survival, growth rate and tissue quality (total fat percentage and colouration). 


\section{Materials and methods}

\section{Experimental fish}

Experiments were conducted at Yellow Island Aquaculture Ltd. (YIAL), which is a Chinook salmon farm located on Quadra Island, British Columbia. In fall 2013, milt was collected from ten male Chinook salmon from each of eight locations in British Columbia ( $n=80$ total males). The males were collected at Chilliwack River, Puntledge River, Nitinat River, Big Qualicum River, Robertson Creek, Capilano River, Quinsam River and YIAL. Eggs were collected from 17 female Chinook salmon from YIAL and pooled. The eggs were then divided into groups of approximately equal numbers, with each group fertilized with the milt of a different male. This design resulted in a total of ten families for each of the eight lines (i.e. paternal locations). The fertilized eggs were reared in Heath incubation trays separated by family until emergence, after which the families from each line were pooled and then moved to $190 \mathrm{~L}$ cylindrical tanks ( 8 tanks per line). Water was continuously aerated, and temperature was maintained at $7-9{ }^{\circ} \mathrm{C}$ by a flow-through system. Fish were kept on a $12 \mathrm{~h}$ light:12 h dark photoperiod and fed to satiation twice daily using Chinook grower feed (Taplow Feeds Inc., Vancouver, British Columbia).

Experimental diets

Two diets were created in collaboration with Taplow Feeds. The control diet was a high fishmeal diet that is the standard Chinook grower feed produced by Taplow Feeds. The experimental diet was a low fishmeal diet designed to match the control diet apart from replacing $75 \%$ of the fishmeal with poultry meal and corn gluten meal (Table 1). Astaxanthin from the algae Haematococcus pluvialis was added to both diets at a concentration of $60 \mathrm{ppm}$ as in the Chinook grower feed produced by Taplow Feeds. The low fishmeal diet also removed $25 \%$ of the fish oil and increased wheat content by $25 \%$. To obtain a crude analysis of diet composition, a sample of each diet was ground to a fine powder and analysed in a Spectrastar 2400 NIR Spectrometer (Unity Scientific Inc.) The crude analysis showed that fat, protein and fibre content of both diets were similar (Table 1). Vitamin A and vitamin E contents were higher and vitamin B content was lower in the high fishmeal diet compared to the low fishmeal diet (Table 1).

Table 1 Ingredients and proximate composition of the high fishmeal and low fishmeal diets

\begin{tabular}{lcr}
\hline & High fishmeal diet & Low fishmeal diet \\
\hline Ingredients & 59 & 15 \\
Fishmeal (\%) & 20 & 15 \\
Fish oil (\%) & 20 & 25 \\
Wheat (\%) & 0 & 16 \\
Poultry meal (\%) & 0 & 28 \\
Corn gluten meal (\%) & 1 & 1 \\
Vitamin premix (\%) & 60 & 60 \\
Astaxanthin (PPM) & & 40 \\
Proximate composition & 40 & 25 \\
Protein (\%) & 24 & 2 \\
Fat (\%) & 3 & 3000 \\
Fibre (\%) & 8000 & 3000 \\
Vitamin A (IU/kg) & 2000 & 135 \\
Vitamin B (IU/kg) & 200 & 4 \\
Vitamin E (IU/kg) & & \\
\hline
\end{tabular}


Growth and survival

In August 2014, fish were PIT tagged to identify individuals. From September 7 to 14, 2014, the tanks were transitioned from freshwater to saltwater. Interval 1 growth rate measurements began on November 24 and 25 , 2014. Fish were anesthetized using a clove oil bath, the PIT tag was read and then total body length and body mass measurements were recorded. After measurements were completed, all fish were moved into two saltwater net pens with 184 fish in the first pen and 196 fish in the second. Both pens remained on the Chinook grower feed (Taplow Feeds Inc.) and were fed twice daily. On December 15, 2014, the second net pen was switched to the low fishmeal diet and these individuals remained on this diet for the duration of the study. On June 25 and 26, 2015, fish were moved from the net pens to the $190 \mathrm{~L}$ tanks in the hatchery, at which point total body length and body mass measurements were repeated for the end of interval 1 . Fish were held in the hatchery for 4 weeks for a separate study of metabolic rates, during which time they continued to be fed the same diet but growth rate was not calculated. Total body length and body mass measurements were taken on July 26, 2015 to start interval 2 and fish were then moved to the net pens, switching the pens of the fish receiving the high and low fishmeal diets. On March 17 and 18, 2016 the final total body length and body mass measurements were taken for the end of interval 2 and fish were euthanized with an overdose of clove oil for tissue analysis. Mortalities were collected three times a week for the duration of the study. Mortality within each diet treatment was calculated for interval 1 and 2, and the hatchery interval from June 2015 to July 2015, based on the number of surviving fish.

Tissue analysis

After euthanization, full body fillets were removed, filleting over the rib bones to ensure removal of the membrane. Total body fat percentage was measured using a Distell fish fat meter (FFM 692; Distell, Scotland, UK) as the average of four readings on the skin side of each fillet, along the lateral line. Tissue colour analysis was performed using the DSM SalmoFan ${ }^{\mathrm{TM}}$ (๔ 2011 Koninklijke DSM N.V.). The colour was analysed using the $20-30$ colour index ( 20 being low red values and 30 being high red values). Fillets were placed skin side down, on a white non-reflective baseboard and observed under indirect sunlight. The fan was closed, then fanned directly above the centre of the fillet in three sections (anterior, dorsal and posterior), and the number corresponding to the most similar colour chip was recorded. This process was repeated for the second fillet from the same fish. Two observers performed independent colour readings for each fish. These colour readings were averaged to obtain whole fillet colouration. Finally, a sample of tissue was taken from the right fillet of each fish, directly in front of the dorsal fin, and immediately frozen for subsequent carotenoid analysis.

\section{Carotenoid analysis}

Carotenoid content was measured in both diets and in a subset of fish from each diet treatment. Carotenoids were extracted after Garner et al. (2010), as described below. All solvents were cooled on ice prior to extraction to prevent retinoid and carotenoid degradation. Three replicates were analysed for each of the high fishmeal and low fishmeal feeds. A total of 37 individuals were analysed for the low fishmeal diet and 36 individuals for the high fishmeal diet. Tissue samples were thawed and homogenized, and then retinoic acid was included as an internal standard to correct for extraction efficiency. The tissue samples were extracted three times in acetone and concentrated, then extracted six times with methyl tert-butyl ether (MtBE) and concentrated, then sealed in an amber glass vial.

HPLC-MS analysis was carried out on an Agilent 1260 HPLC coupled with a 6230 TOF-MS (Agilent technologies, USA). Shortly after extraction, samples $(25 \mu \mathrm{L})$ were injected onto a Poroshell 120 EC-C18 column $(3.0 \times 50 \mathrm{~mm}, 2.7 \mu \mathrm{m}$, Agilent technologies, USA) and eluted with a solvent gradient as follows: an isocratic flow of solvent "A" (methanol-water, 8:1) was maintained at 100\% from time 0-4 min, followed by a linear gradient to $100 \%$ Solvent "B" (methanol-hexanes, 4:1) over 2.5 min followed by an isocratic flow at $100 \%$ for $10 \mathrm{~min}$ before the mobile phase was switched over to $100 \% \mathrm{~A}$ and maintained for an additional $7 \mathrm{~min}$ for equilibration before the next injection. The HPLC flow rate was $0.5 \mathrm{~mL} / \mathrm{min}$ and the column temperature was maintained at $25{ }^{\circ} \mathrm{C}$. Retinoic acid and astaxanthin were detected at $325 \mathrm{~nm}$ and $480 \mathrm{~nm}$, respectively, prior to infusion into the TOF. For LC-MS measurements, the LC was coupled to the TOF-MS 
with an atmospheric pressure chemical ionization (APCI) interface, operating in positive ionization mode. Nitrogen was used as the drying gas at a flow rate of $5 \mathrm{~L} / \mathrm{min}$, and was maintained at $350{ }^{\circ} \mathrm{C}$ with a nebulizer pressure of $60 \mathrm{psi}$. The Corona needle was operated at $4 \mu \mathrm{A}(5235 \mathrm{~V})$. The capillary was operated at $6.1 \mu \mathrm{A}$ with a cone voltage of $3500 \mathrm{~V}$. The vaporizer chamber temperature was set to $350{ }^{\circ} \mathrm{C}$, and dry gas temperature was held at $350{ }^{\circ} \mathrm{C}$. Astaxanthin in sample extracts was identified and compared using the chromatographic retention times and full-scan mass spectra derived from an astaxanthin reference standard (Sigma 0982). Retinoic acid was included in sample extracts as an internal standard, and was identified and compared alongside a reference standard (Sigma R2625). Both standards were prepared and diluted to $0.01 \mathrm{mg} / \mathrm{mL}$ and run alongside the samples under the same conditions. Retinoic acid $\left(\mathrm{C}_{20} \mathrm{H}_{28} \mathrm{O}_{2}\right.$, exact mass 300.4351$)$ reference standard was found at $301.2171 \mathrm{~m} / \mathrm{z}\left([\mathrm{M}+\mathrm{H}]^{+}\right)$, while the astaxanthin $\left(\mathrm{C}_{40} \mathrm{H}_{52} \mathrm{O}_{4}\right.$, exact mass $596.3865)$ reference standard was found at $597.3847 \mathrm{~m} / \mathrm{z}\left([\mathrm{M}+\mathrm{H}]^{+}\right)$. Astaxanthin levels in the samples were then calculated as the area of the astaxanthin absorbance peak divided by the mass of the sample and corrected using the area of the internal standard (retinoic acid) peak.

Statistical analysis

Growth rate for each interval was calculated as GR $=\left(\ln \left(W_{1}\right)-\ln \left(W_{0}\right) / T\right) \times 100$, where $W_{0}$ is the individual's initial body mass, $W_{1}$ is the individual's final body mass, and $T$ is the number of days between body mass measurements. Growth rate, SalmoFan colour values, carotenoid concentrations and tissue fat percentages were each analysed using an ANOVA with diet (high fishmeal and low fishmeal) as a fixed factor. Line was included as a random factor in the ANOVAs. Survivorship was analysed using a Fisher's exact test to compare the number of survivors and mortalities between the two diet treatments within each sampling period. Pearson's correlation was used to compare the colour card values with corresponding astaxanthin tissue values. All statistical analyses were performed using R (V.0.99.484, RStudio, Inc.; www.rstudio.com) or JMP (v4.0.4, SAS Institute Inc., Cary, NC, U.S.A.).

\section{Results}

At the start of the study, neither total body length nor body mass differed between the fish assigned to the two diet treatments (Table 2). At the following measurement point (June 2015), individuals on the high fishmeal diet were $3 \%$ longer than individuals on the low fishmeal diet $\left(F_{1,308}=4.56, p=0.035\right.$; Table 2$)$. There was no significant difference in body length for the remaining measurement points in the study (Table 2). Body mass did not differ between diet treatments during the entirety of the study (all $p>0.05$ ) (Table 2). There was no significant difference in growth rate between fish from the two diet treatments during the first interval

Table 2 Body mass and total body length of Chinook salmon (Oncorhynchus tshawytscha) fed either the high fishmeal or low fishmeal diets at four sampling points

\begin{tabular}{|c|c|c|c|c|}
\hline & November 2014 & June 2015 & July 2015 & March 2016 \\
\hline \multicolumn{5}{|l|}{ Body mass (g) } \\
\hline High fishmeal & $27.3 \pm 5.9$ & $184.6 \pm 49.8$ & $184.3 \pm 54.0$ & $498.5 \pm 118.0$ \\
\hline Low fishmeal & $27.5 \pm 7.0$ & $172.9 \pm 50.9$ & $190.2 \pm 62.7$ & $467.4 \pm 131.2$ \\
\hline Test statistics & $\begin{array}{l}F_{1,366}=1.05 \\
p=0.30\end{array}$ & $\begin{array}{l}F_{1,309}=1.14 \\
p=0.28\end{array}$ & $\begin{array}{l}F_{1,189}=0.11 \\
p=0.74\end{array}$ & $\begin{array}{l}F_{1,99}=3.01 \\
p=0.08\end{array}$ \\
\hline \multicolumn{5}{|c|}{ Body length (mm) } \\
\hline High fishmeal & $140 \pm 9$ & $262 \pm 27$ & $268 \pm 24$ & $355 \pm 34$ \\
\hline Low fishmeal & $140 \pm 10$ & $255 \pm 30$ & $261 \pm 27$ & $341 \pm 50$ \\
\hline Test statistics & $\begin{array}{l}F_{1,366}=0.05 \\
p=0.82\end{array}$ & $\begin{array}{l}F_{1,309}=4.56 \\
p=0.035\end{array}$ & $\begin{array}{l}F_{1,189}=3.01 \\
p=0.09\end{array}$ & $\begin{array}{l}F_{1,99}=2.70 \\
p=0.12\end{array}$ \\
\hline
\end{tabular}

Test statistics ( $F$ statistic, degrees of freedom, $p$ value) are included for the ANOVAs comparing body mass and body length between diets at each measurement point. Means \pm SD are presented 
$\left(F_{1,311}=3.62, p=0.058\right.$; Fig. $\left.1 \mathrm{a}\right)$ or the second interval $\left(F_{1,91}=1.48, p=0.23\right.$; Fig. $\left.1 \mathrm{~b}\right)$. There was no significant difference in survival during any of the measurement intervals (all $p>0.05$ ) (Table 3 ).

The diets had a significant effect on multiple aspects of salmon tissue quality (tissue fat and tissue colouration). Individuals fed the low fishmeal diet had $25 \%$ higher total body fat percentage than those fed the high fishmeal diet $\left(F_{1,91}=4.58, p=0.035\right.$; Fig. 2$)$. Individuals on the low fishmeal diet also had lighter coloured flesh than those on the high fishmeal diet $\left(F_{1,91}=33.51, p<0.001\right.$; Fig. 3a). Carotenoid analysis was consistent with the tissue colour results; astaxanthin levels in salmon fed the low fishmeal diet were significantly lower than in salmon fed the high fishmeal diet $\left(F_{1,64}=10.98, p=0.002\right.$; Fig. 3b). As expected, there was a significant positive correlation between red colouration and astaxanthin levels in the flesh $\left(F_{1,70}=53.76, p<0.001 ; r^{2}=0.43\right)$. LC-MS analysis of carotenoid content in feed pellets showed no significant difference in astaxanthin levels between the high and low fishmeal diets (Mean $\pm \mathrm{SD}$; high fishmeal diet $=0.93 \pm 0.24$ absorbance $/ \mathrm{mg}$ feed; low fishmeal diet $=1.57 \pm 0.62$ absorbance $/ \mathrm{mg}$ feed; $F_{1,4}=2.80, p=0.17$.

\section{Discussion}

Aquaculture diets that replace fishmeal with plant or animal meal could influence the health and survival of fishes if they do not provide an adequate source of all essential nutrients. In previous studies, alternative diets that replaced fishmeal with a combination of poultry and plant-based ingredients were associated with no change in survival (Burr et al. 2012; Lu et al. 2015). In our study, Chinook salmon were fed a diet that replaced $75 \%$ of fishmeal with a combination of corn gluten meal and poultry meal, and we similarly found no difference in survival between diets. Alternative aquaculture diets likely have not been found to affect survival because these diets are specifically formulated to provide all essential nutrients. Indeed, the alternative diet in our study had the same composition of protein, fat, and fibre as the high fishmeal feed, which is formulated based on the needs of salmonids (National Research Council 1993). Overall, reduced survival does not appear to be a barrier to the inclusion of plant or animal meal in alternative aquaculture diets for salmon.

Aquaculture diets that include plant or animal meal can also affect growth rate. Our study found no difference in growth rates in Chinook salmon fed the alternative diet versus the conventional diet. These results are consistent with previous studies that found that diets containing a combination of poultry meal and
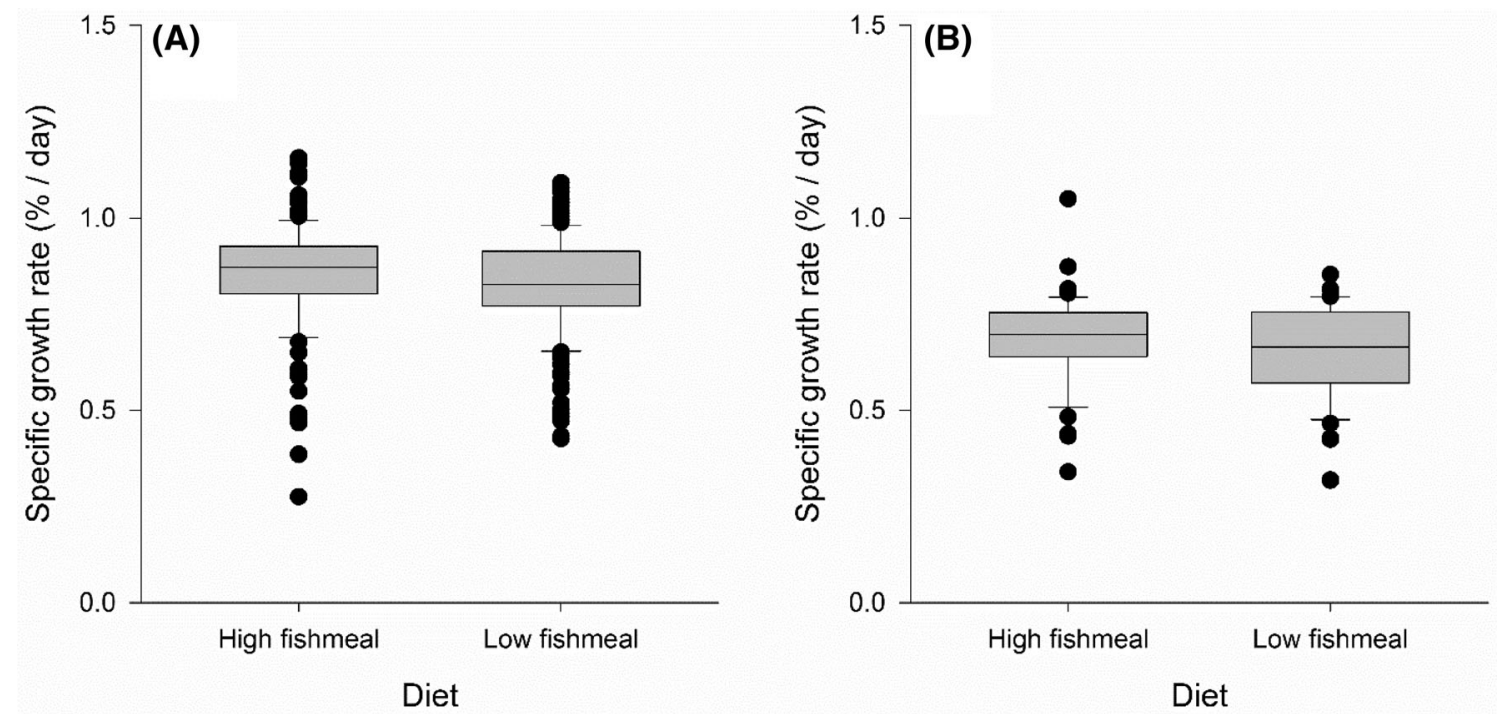

Fig. 1 Specific growth rate (\% body mass/day) of Chinook salmon (Oncorhynchus tshawytscha) fed either a high fishmeal or low fishmeal diet. Boxes show the 25 th and 75 th percentile with a line indicating the median. Whiskers show the 10th and 90 th percentile. Individuals outside of this range are indicated with a black dot. a Interval 1, which occurred from November 2014 to June 2015, and b interval 2 which occurred from July 2015 to March 2016. Growth rate did not differ significantly between diets for either interval 
Table 3 Survivorship of Chinook salmon (Oncorhynchus tshawytscha) fed either the high fishmeal or low fishmeal diet during three intervals. Significance is based on a Fisher's exact test comparing survivors and mortalities between diets at each measurement time

\begin{tabular}{llccccc}
\hline & Diet & Total & Survivors & Mortalities & \% Survival & Significance \\
\hline November 2014-June 2015 & High fishmeal & 192 & 154 & 38 & 80.2 & 0.89 \\
& Low fishmeal & 185 & 150 & 35 & 81.0 & \\
June 2015-July 2015 & High fishmeal & 154 & 82 & 72 & 52.9 & 0.08 \\
& Low fishmeal & 150 & 65 & 85 & 42.9 & \\
July 2015-March 2016 & High fishmeal & 82 & 50 & 32 & 60.5 & 0.11 \\
& Low fishmeal & 65 & 48 & 17 & 73.4 & \\
Total & High fishmeal & 192 & 50 & 142 & 26.0 & 1.00 \\
& Low fishmeal & 185 & 48 & 136 & 25.9 & \\
\hline
\end{tabular}

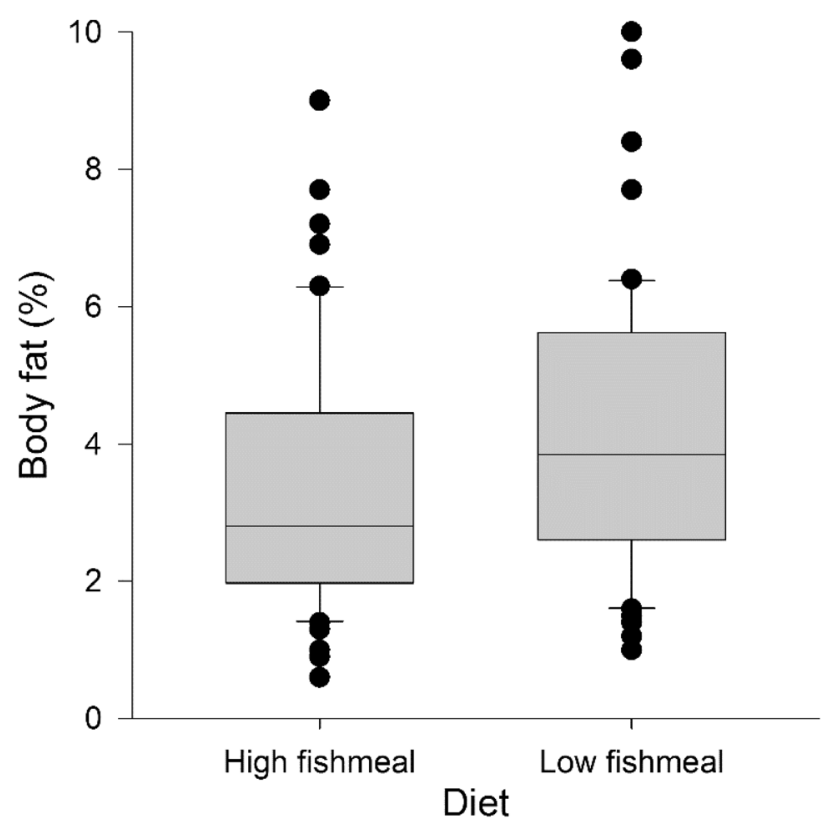

Fig. 2 Total body fat (\% body composition) of Chinook salmon (Oncorhynchus tshawytscha) fed either a high fishmeal or low fishmeal diet. Boxes show the 25th and 75th percentile with a line indicating the median. Whiskers show the 10th and 90th percentile. Individuals outside of this range are indicated with a black dot. Fish fed the low fishmeal diet had significantly higher body fat than those fed the high fishmeal diet

other plant protein sources result in growth rates comparable to standard fishmeal diets (e.g. Burr et al. 2012; Hatlen et al. 2015). The success of these diets that combine poultry meal and plant protein sources is likely because combinations of protein meals produce a more balanced amino acid composition and increased digestible protein:energy ratio than either plant or animal protein meal only. Indeed, plant protein sources generally have lower levels of lysine, methionine, arginine, and tryptophan compared to fishmeal, whereas poultry meal has a similar amino acid composition to fishmeal (Mente et al. 2003; National Research Council 2011). Together, these data suggest that poultry meal in combination with a plant-based meal can be incorporated at high levels into alternative aquaculture diets with no adverse effect on growth rate.

Plant-based meal and poultry meal differ from fishmeal in fat content and fatty acid composition, which could influence body fat in fishes. We found that fish fed a diet that included poultry and corn gluten meal had $25 \%$ higher total body fat than fish fed the high fishmeal diet. This difference in body fat occurred despite the similar fat content of the two diets (High fishmeal $=24 \%$, Low fishmeal $=25 \%$ ). However, the diets differed in fatty acid composition: both poultry meal and corn gluten meal are low in omega-3 fatty acids, poultry meal 

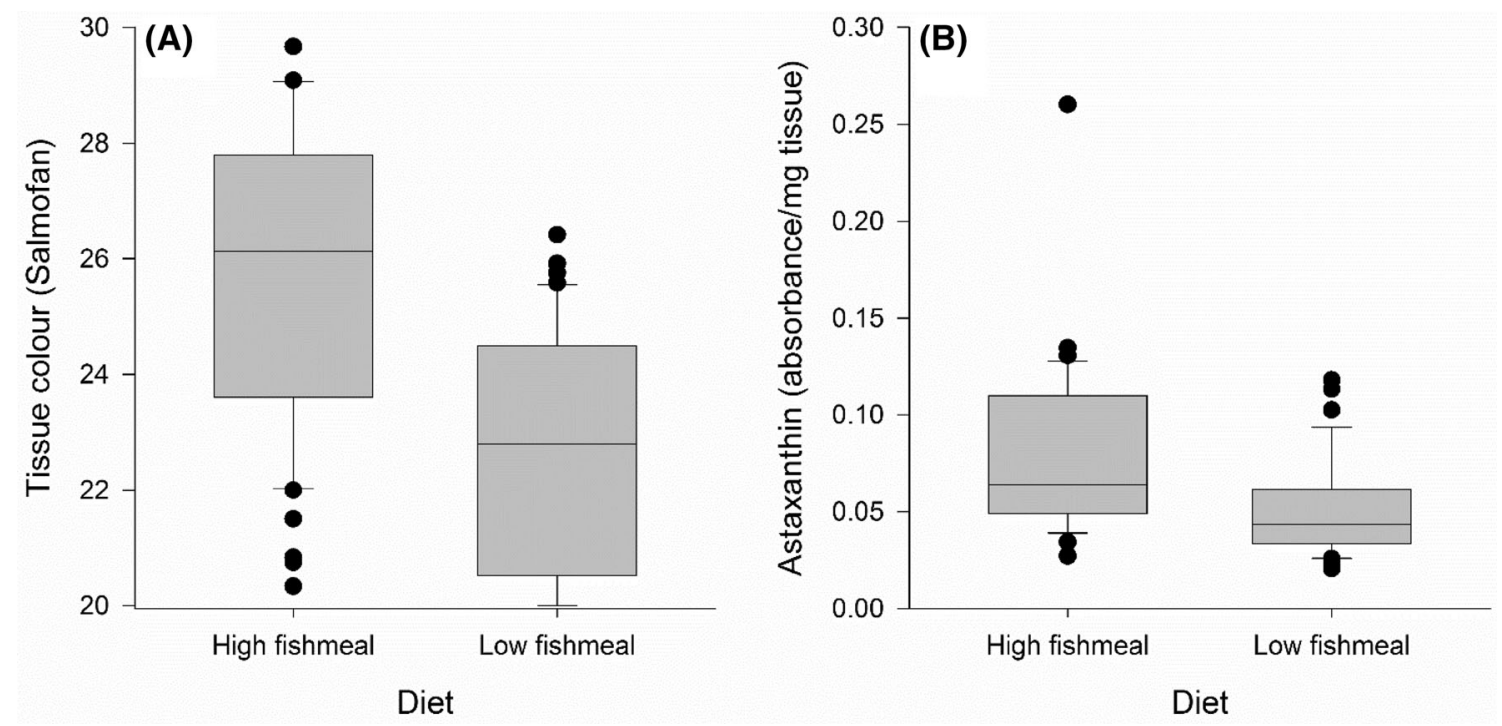

Fig. 3 Tissue colour and astaxanthin levels for Chinook salmon (Oncorhynchus tshawytscha) fed either a high fishmeal or low fishmeal diet. Boxes show the 25th and 75th percentile with a line indicating the median. Whiskers show the 10th and 90th percentile. Individuals outside of this range are indicated with a black dot. a Tissue colour based on the SalmoFan colour card measurements, which use a scale of 20 (least red) to 30 (most red). b Astaxanthin levels as the absorbance/mg tissue after correcting for sample extraction efficiency using an internal standard. Both tissue colour and astaxanthin levels were significantly different between diets

is rich in saturated and monounsaturated fatty acids, whereas fishmeal is rich in omega-3 and polyunsaturated fatty acids (National Research Council 2011). Salmon require high levels of polyunsaturated fatty acids in their diets and low levels of saturated fatty acids (Parés-Sierra et al. 2014; Sargent et al. 1999). Saturated fatty acids that are not required for other functions may be more likely to accumulate in tissues such as muscle. Differences in fatty acid composition between the diets may have led to increased fat storage in the fish fed the diet containing the poultry meal and corn gluten meal substitution. Regardless, the low fishmeal diet did not lead to a reduction in total body fat.

In salmonids, diets containing corn gluten meal have been associated with reduced concentrations of astaxanthin and the associated red tissue colouration (Saez et al. 2014, 2016). Consistent with these findings, in our study the individuals fed the alternative diet that contained corn gluten meal had a significant reduction in tissue redness and tissue astaxanthin levels relative to the fish fed the high fishmeal diet. Astaxanthin was added to both diets in equal concentrations and HPLC analysis showed no difference in astaxanthin levels between the diets, so a difference in diet-based astaxanthin levels cannot explain the deficiency. Instead, the difference in tissue colouration may occur because of dilution from novel xanthophylls present in the alternative feed. Similar to astaxanthin, these novel xanthophylls are absorbed in the gut and deposited in the flesh, but these xanthophylls do not impart the same distinctive red colour (Furr and Clark 1997; Olsen and Baker 2006). Based on previously reported concentrations of xanthophylls (lutein, zeaxanthin) in corn gluten meal (150-500 mg/kg; Moros et al. 2002; Park et al. 1997) and a 28\% contribution of corn gluten meal to the low fishmeal diet, our low fishmeal diet likely contained these xanthophylls at concentrations that were similar to astaxanthin (estimated $40-140 \mathrm{mg} / \mathrm{kg}$ for the xanthophylls versus $60 \mathrm{mg} / \mathrm{kg}$ for the astaxanthin). Passive interference by other xanthophylls may have contributed to an overall dilution of astaxanthin levels in our study.

Another explanation for decreased tissue colouration could be that the two diets led to differences in astaxanthin utilization. Up to half of the astaxanthin absorbed by salmon can be metabolized to Vitamin A (Torrissen et al. 1989), especially when dietary levels of vitamin A are low (Goodwin 1986; Matsuno 1991).Our alternative diet had 60\% less vitamin A (3000 IU/kg) compared to the high fishmeal diet (8000 IU/ $\mathrm{kg}$ ). Dietary requirements for vitamin A in Oncorhynchus species are reported to range from about 2500 to $7000 \mathrm{IU} / \mathrm{kg}$ (De Silva and Anderson 1994). It is conceivable that the alternative diet provided insufficient Vitamin A, leading to greater conversion of astaxanthin to vitamin A and consequently reduced astaxanthin 
concentrations in the muscle tissue. Overall, our study adds to the growing evidence that the inclusion of corn gluten meal in salmon diets is associated with reduced astaxanthin levels in the flesh, albeit the specific mechanism leading to this effect is not yet resolved.

Due to the importance of tissue colouration in marketability of salmon, a corn gluten and poultry meal diet combination cannot be used in its present formulation in salmon aquaculture. Corn gluten meal is a costeffective and readily available ingredient, but appears to be the cause of reduced tissue astaxanthin concentrations and colouration. Given the potential contribution of astaxanthin utilization for vitamin A synthesis, further study is warranted to determine if the addition of greater concentrations of vitamin A to the alternative diet can mitigate the effect on colour. A side from this adverse effect, our study adds to the growing evidence that poultry meal, in combination with another plant protein source, is a viable alternative to high concentrations of fishmeal in salmonid diets.

Acknowledgements We thank B. Hicks of Taplow Feeds for developing and producing the feeds for this experiment, A. Heath and the staff at Yellow Island Aquaculture for their support with fish husbandry, and A. Houde and K. Mitchell for assistance with data collection. All experiments followed the ethical guidelines from the Canadian Council on Animal Care as approved by the Animal Use Subcommittees at Western University (protocol 2010-214). This study was supported by an NSERC of Canada Strategic Partnership Grant to B. Neff.

\section{Compliance with ethical standards}

Conflict of interest The authors declare that they have no conflict of interest.

Ethical approval All applicable national and institutional guidelines for the care and use of animals were followed by the authors.

Open Access This article is distributed under the terms of the Creative Commons Attribution 4.0 International License (http:// creativecommons.org/licenses/by/4.0/), which permits unrestricted use, distribution, and reproduction in any medium, provided you give appropriate credit to the original author(s) and the source, provide a link to the Creative Commons license, and indicate if changes were made.

\section{References}

Anderson S (2001) Salmon color and the consumer. In: Johnston RS, Shriver AL (eds) Proceedings of the tenth biennial conference of the International Institute of Fisheries economics and trade presentations. Oregon State University, Corvallis, pp 1-3

Bjerkeng B, Refstie S, Fjalestad KT, Storebakken T, Rødbotten M, Roem AJ (1997) Quality parameters of the flesh of Atlantic salmon (Salmo salar) as affected by dietary fat content and full-fat soybean meal as a partial substitute for fish meal in the diet. Aquaculture 157:297-309

Burr GS, Wolters WR, Barrows FT, Hardy RW (2012) Replacing fishmeal with blends of alternative proteins on growth performance of rainbow trout (Oncorhynchus mykiss), and early or late stage juvenile Atlantic salmon (Salmo salar). Aquaculture 334-337:110-116

De Silva SS, Anderson TA (1994) Fish nutrition in aquaculture. Springer, Berlin

Fowler LG (1991) Poultry by-product meal as a dietary protein source in fall chinook salmon diets. Aquaculture 99:309-321

Furr HC, Clark RM (1997) Intestinal absorption and tissue distribution of carotenoids. J Nutr Biochem 8:364-377

Garner SR, Neff BD, Bernards MA (2010) Dietary carotenoid levels affect carotenoid and retinoid allocation in female Chinook salmon Oncorhynchus tshawytscha. J Fish Biol 76:1474-1490

Gatlin DM, Barrows FT, Brown P, Dabrowski K, Gaylord TG, Hardy RW, Herman E, Hu G, Krogdahl Å, Nelson R, Overturf K, Rust M, Sealey W, Skonberg D, Souza EJ, Stone D, Wilson R, Wurtele E (2007) Expanding the utilization of sustainable plant products in aquafeeds: a review. Aquac Res 38:551-579

Goodwin TW (1986) Metabolism, nutrition, and function of carotenoids. Annu Rev Nutr 6:273-297

Hatlen B, Jakobsen J-V, Crampton V, Alm M, Langmyhr E, Espe M, Hevrøy EM, Torstensen BE, Liland N, Waagbø R (2015) Growth, feed utilization and endocrine responses in Atlantic salmon (Salmo salar) fed diets added poultry by-product meal and blood meal in combination with poultry oil. Aquac Nutr 21:714-725

Lu F, Haga Y, Satoh S (2015) Effects of replacing fish meal with rendered animal protein and plant protein sources on growth response, biological indices, and amino acid availability for rainbow trout Oncorhynchus mykiss. Fish Sci 81:95-105

Mambrini M, Roem AJ, Carvedi JP, Lalles JP, Kaushik SJ (1999) Effects of replacing fish meal with soy protein concentrate and of DL-methionine supplementation in high-energy, extruded diets on the growth and nutrient utilization of rainbow trout, Oncorhynchus mykiss. J Anim Sci 77:2990-2999

Matsuno T (1991) Xanthophylls as precursors of retinoids. Pure Appl Chem 63:81-88

Mente E, Deguara S, Santos M, Houlihan D (2003) White muscle free amino acid concentrations following feeding a maize gluten dietary protein in Atlantic salmon (Salmo salar L.). Aquaculture 225:133-147 
Moreno JA, Díaz-Gómez J, Nogareda C, Angulo E, Sandmann G, Portero-Otin M, Serrano JCE, Twyman RM, Capell T, Zhu C, Christou P (2016) The distribution of carotenoids in hens fed on biofortified maize is influenced by feed composition, absorption, resource allocation and storage. Sci Rep 6:35346

Moros EE, Darnoko D, Cheryan M, Perkins EG, Jerrell J (2002) Analysis of xanthophylls in corn by HPLC. J Agric Food Chem 50:5787-5790

Mundheim H, Aksnes A, Hope B (2004) Growth, feed efficiency and digestibility in salmon (Salmo salar L.) fed different dietary proportions of vegetable protein sources in combination with two fish meal qualities. Aquaculture 237:315-331

National Research Council (1993) Nutrient requirements of fish. The National Academies Press, Washington, DC

National Research Council (2011) Nutrient requirements of fish and shrimp. The National Academies Press, Washington, DC

Olsen RE, Baker RTM (2006) Lutein does not influence flesh astaxanthin pigmentation in the Atlantic salmon (Salmo salar L.). Aquaculture 258:558-564

Parés-Sierra G, Durazo E, Ponce MA, Badillo D, Correa-Reyes G, Viana MT (2014) Partial to total replacement of fishmeal by poultry by-product meal in diets for juvenile rainbow trout (Oncorhynchus mykiss) and their effect on fatty acids from muscle tissue and the time required to retrieve the effect. Aquac Res 45:1459-1469

Park H, Flores RA, Johnson LA (1997) Preparation of fish feed ingredients: reduction of carotenoids in corn gluten meal. J Agric Food Chem 45:2088-2092

Saez PJ, Abdel-Aal E-SM, Bureau DP (2014) Reduction of carotenoids in corn gluten meal: effects on growth performance and muscle pigmentation of rainbow trout (Oncorhynchus mykiss). Can J Anim Sci 95:79-92

Saez PJ, Abdel-Aal E-SM, Bureau DP (2016) Feeding increasing levels of corn gluten meal induces suboptimal muscle pigmentation of rainbow trout (Oncorhynchus mykiss). Aquac Res 47:1972-1983

Sargent J, Bell G, McEvoy L, Tocher D, Estevez A (1999) Recent developments in the essential fatty acid nutrition of fish. Aquaculture 177:191-199

Sealey WM, Hardy RW, Barrows FT, Pan Q, Stone DAJ (2011) Evaluation of $100 \%$ fish meal substitution with chicken concentrate, protein poultry by-product blend, and chicken and egg concentrate on growth and disease resistance of juvenile rainbow trout, Oncorhynchus mykiss. J World Aquac Soc 42:46-55

Steffens W (1994) Replacing fish meal with poultry by-product meal in diets for rainbow trout, Oncorhynchus mykiss. Aquaculture 124:27-34

Torrissen O, Hardy R, Shearer K (1989) Pigmentation of salmonids-carotenoid deposition and metabolism. CRC Crit Rev Aquat Sci 1:209-225

\section{Publisher's Note}

Springer Nature remains neutral with regard to jurisdictional claims in published maps and institutional affiliations. 